\title{
Sub-adult Ravens Synchronize their Play: A Case of Emotional Contagion?
}

\begin{abstract}
Mathias Osvath $^{1^{*}}$ and Miriam Sima ${ }^{2}$
${ }^{1}$ Lund University

${ }^{2}$ Max Planck Institute for Ornithology

*Corresponding author (Email: mathias.osvath@lucs.lu.se)

Citation - Osvath, M., \& Sima, M. (2014). Sub-adult ravens synchronize their play: A case of emotional contagion? Animal Behavior and Cognition, 1(2), 197-205. doi: 10.12966/abc.05.09.2014

Abstract - Emotional contagion - the alignment of emotions between individuals through behavioral synchronization - is proposed as a key, basic component of human social cognition and empathy. In the field of cognitive zoology, contagious behaviors have also received attention. Several such behaviors have been documented in various species. Nevertheless, emotional and behavioral contagion differ. Emotional contagion - a term predominantly used in human psychology - requires that the contagious behavior leads to converging emotional states. In non-linguistic animals, it is difficult to determine whether a behavior "caught" from someone else results in a similar affective state or remains a purely behavioral response. Some studies suggest the latter as a possibility. To disentangle the problem, we explored instances of contagious behaviors within the play domain. In several species, play involves a variety of behaviors falling into different categories: social, object and locomotor play. If a category of play in one individual induces a different category of play in another, this suggests the spread of a generally playful mood rather than a species-specific motor response. Although some studies suggest emotional contagion in mammals, it is not known whether it occurs in birds. We investigated play contagion in a group of ravens, well known for their complex social skills. The results indicate emotional contagion: the birds engaged in all categories of play on a higher level under the condition where contagion was likely to occur.
\end{abstract}

Keywords - Emotional contagion, Behavioral synchronization, Social cognition, Animal play, Empathy, Raven cognition

Synchronizing one's behavior with others reduces the risk from individual trial-and-error learning and performs important social functions (e.g., Boyd \& Richerson, 1988; Preston \& de Waal, 2002). Behavioral synchronization in animals and humans has been widely studied; psychological mechanisms of varying complexity have been proposed. At the pinnacle of complexity is imitation, which can be defined as the copying of novel behaviors not included in one's innate repertoire. At the other end of the spectrum lie released, species-specific behaviors. (For a comprehensive account see Zentall, 2001.)

In recent years, lower-level mechanisms for behavioral synchronization have received much attention, mainly because of their importance to pro-social processes. Contagious yawning - the spreading of yawns between individuals - has attracted particular interest, having been documented in several species. Synchronization of yawning has been suggested to imply emotional contagion: the alignment of one's emotions with the other is a process believed to be a foundation of empathy (Preston $\&$ de Waal, 2002). This assumption has been strengthened by results showing that yawns are more contagious between familiar than unfamiliar individuals (e.g., Campbell \& de Waal, 2011). Human psychology regards emotional contagion as a fundamental part of human sociality and cognition essential 
for developing “mind-reading” skills (e.g., Hatfield, Rapson, \& Le, 2009) - making it of great interest whether, and in what forms, emotional contagion occurs in non-human animals. Some studies on mammals hint this direction: a study on contagious yawning in dog pups (Canis lupus familiaris) found that several subjects got sleepy during the yawning sessions (Madsen \& Persson, 2013). Studies on orangutans (Pongo pygmaeus) and geladas (Theropithecus gelada) have revealed rapid facial mimicry in play activities, something thought to suggest emotional contagion (Mancini, Ferrari, \& Palagi, 2013; Ross, Menzler, \& Zimmerman, 2008). Despite several reports of social learning and behavioral synchronization in birds (Zentall, 2004), one finds no studies on emotional contagion in birds. Such findings could be valuable toward understanding the independent evolution of sociality, as birds and mammals share a last common ancestor as far back as 300 million years ago.

Behavioral and emotional contagion differ importantly in meaning. Contagious behaviors occur when an unlearned species-typical behavior arises in an individual instigated by a demonstrator performing that behavior (e.g., Zentall, 2001). Such patterns are seen in fleeing bird flocks and herds of mammals. Emotional contagion requires that the copied behavior leads to an affective state similar to the demonstrator's (e.g., Hatfield et al., 2009).

It is not trivial to tease apart any emotional component from released, species-specific behaviors in animals (e.g., when catching a yawn, a specific, innate motor pattern is performed that could be unrelated to any emotions). The question is: does the behavior of the other not only produce the same behavior in the receiver but also the same affective state, or is the behavior transmitted without such emotional correlates? Examples do exist of behavior being copied seemingly without the corresponding affective state: e.g., when satiated chickens feed because a conspecific starts to feed nearby (Tolman, 1964). This qualifies as behavioral but not emotional contagion.

Defined in this strict sense, the requirement that emotional contagion involve copied behaviors might be too narrow: e.g., some (de Waal, 2008) see emotional contagion in a study where mice became more sensitive to pain having witnessed a fellow mouse exhibiting pain responses (Langford et al., 2006). The observer appears to perceive the agony of the other and be put in a more sensitive state towards similar stimuli, but no performance of analogous behavior is involved. One finds other examples where animals are affected by the emotional state of another without any observation of copied behavior. That said, the lack of any visibly similar behavior between observer and demonstrator might result from a failure to measure it. The behaviors could have been subtle facial or vocal mimicry or shifts of body posture; or perhaps there were mental simulations not expressed in any overt behavior. (For an overview see Hatfield et al., 2009). One can speculate on at least two different causal processes: one where the behavior is copied without any emotional correlate but the action brings the copier into a similar emotional state, the other where the emotion of the originator instigates the behavioral copying such that "emotion reading" comes first. However, these questions along with their possible evolutionary underpinnings lie outside the scope of this study.

Play is a well-suited candidate behavior that could aid in separating emotional components from released motor patterns. It is associated with a mood and has no immediate biological benefit. Even if play likely brings long-term gains in fitness, it is proximately performed for its own sake. (For a comprehensive review of play and criteria for it, see Burghardt, 2005.). Species with a complex play repertoire express radically different motor patterns, some of which are learned. If a category of play in one individual induces a different category in another, this suggests the spread of a playful mood rather than released, species-specific behavior. Such a process would qualify as emotional contagion. The apparent contagiousness of play in groups of animals has been widely noted (e.g., Baerends, 1989; Baldwin \& Baldwin, 1974; Bekoff \& Byers, 1981; Fagen, 1981; Gamble \& Cristol, 2002; Gomendio, 1988; Gwinner, 1966 ), and Held and Špinka (2011) have proposed that the spread of play might be a case of emotional contagion.

Only a very few studies have been dedicated to contagious play, including the aforementioned studies on rapid facial mimicry in primates. Systematic studies show that social play in rats increases when a playful individual is introduced to a less playful one (Pellis \& McKenna, 1992; Varlinskaya, Spear, \& Spear, 1999). To our knowledge, however, no one has studied whether one category of play 
induces another category of play in others: something that would be a good indication of emotional contagion. We investigated this question in a group of sub-adult common ravens (Corvus corax).

Ravens are known for their complex play and are, indeed, regarded as among the most playful of animals (e.g., Ficken, 1977; Heinrich \& Smolker, 1998). Ravens engage in all three broad categories of play: social, object, and locomotor; they also invent novel combinations of play. Gwinner's (1966) report on a group of captive ravens mimicking a new type of play invented by one individual, suggests advanced behavioral synchronization. Ravens are therefore well suited for studying emotional contagion in play. We investigated whether object play in one individual leads to increased locomotor and social play in the group.

\section{Method}

At Lund University's Corvid Cognition Station, we observed a group of seven captive sub-adult ravens: four males and three females between 10 and 11 months old. The dominance hierarchy in the group was well-established. We used one of the ravens' everyday aviaries $\left(176 \mathrm{~m}^{2}\right.$ in area and five meters in height). There were no restrictions on feeding or other care routines.

We used three conditions: "baseline," "toy," and "food." The baseline condition measured play behaviors without any interventions. The toy condition measured play behaviors after introduction of an item known to elicit object play in the individual holding it. Here, our intention was to reveal potential contagion. The food condition measured play behaviors when a favored food item was given to an individual who would try to consume rather than play with it. This was similar to the toy condition: the item was likewise highly desirable for the ravens, but for different reasons than the toy.

Toys were selected to be of a character known to elicit intense play in enrichment activities: small stuffed animals and large plastic insects, ranging from eight to fifteen centimeters in length. Food was selected on the basis of previously established favorite food items: medium-sized (approximately 10$5 \times 5 \times 5 \mathrm{~cm}$ ) chunks of cheese, meat and baked goods. (See Figure 1.)

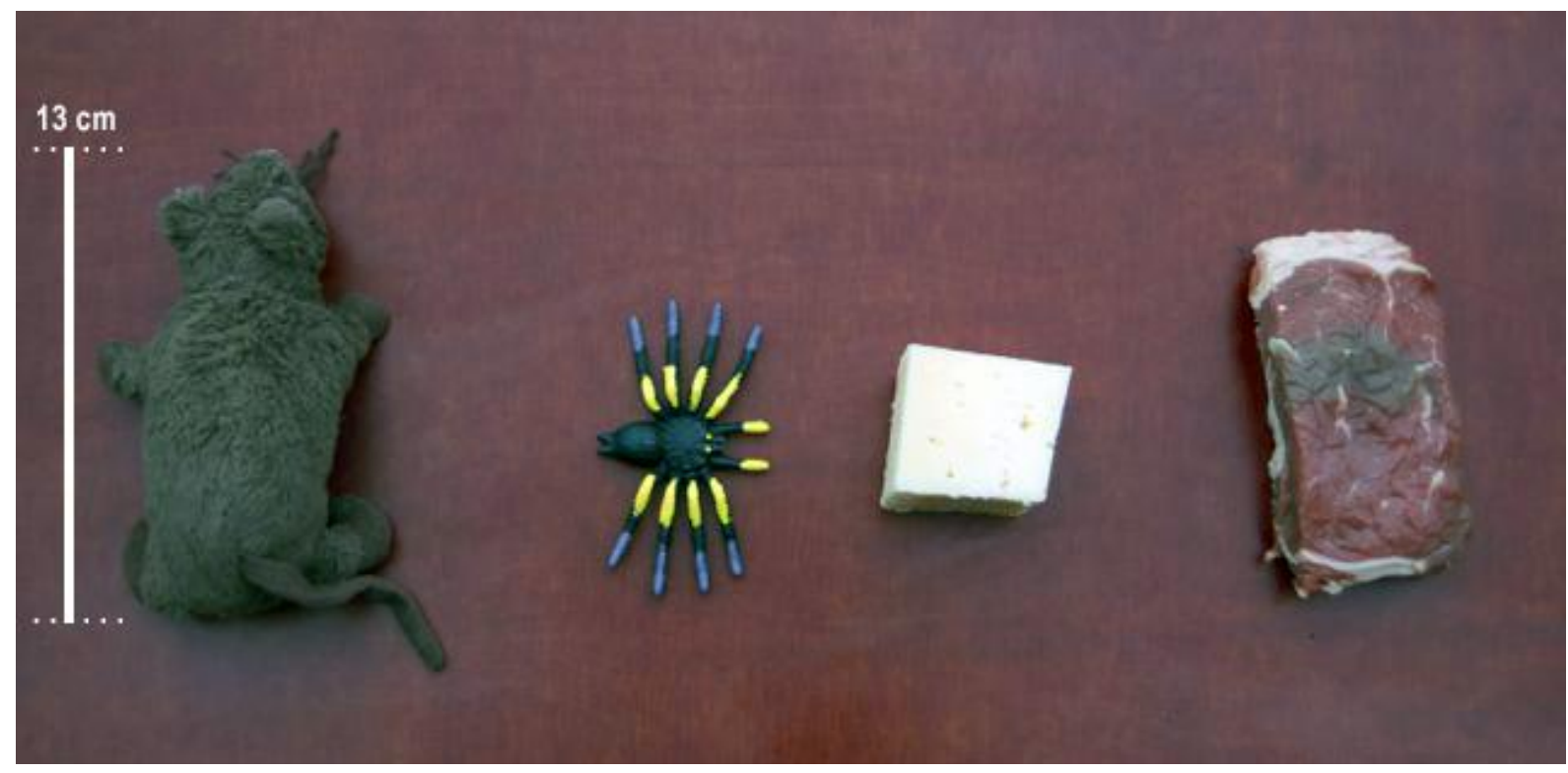

Figure 1. Examples of toys and food items used in the different conditions. From left to right: a stuffed toy rat, a colorful plastic spider, a piece of cheese, and a piece of meat.

The three conditions were counterbalanced over the 48 days in which we performed the study. Baseline consisted of eleven sessions lasting an average of $25 \mathrm{~min}$, for a total of $279 \mathrm{~min}$. For "toy," the experimenter gave one of the ravens a toy. In half the sessions, the bird was the group's dominant raven, 
in half the most subordinate raven. The item was small enough to be monopolized by one individual yet large enough to be stolen. A session ended when no individual had manipulated the toy for five minutes. Eight sessions were conducted lasting an average length of $34 \mathrm{~min}$, for a total of $273 \mathrm{~min}$. Four toys were used, counterbalanced between receivers. "Food" was as per "toy" but, instead of a toy, a favored food item was given in an equal distribution to the dominant and to the subordinate bird. The food item was small enough to be monopolized but large enough not to be immediately consumed; initially, it was large enough to be stolen. A session ended when the food was either consumed or small enough to be hidden in a beak. Eight sessions were conducted lasting an average of $21 \mathrm{~min}$, for a total of $170 \mathrm{~min}$. Four food types were used. Sessions under all conditions were counterbalanced before and after daily feeding.

All sessions were video recorded and the video analyzed. Inter-observer agreement was high (Kappa = 0.86). In the toy and food conditions, we coded the behaviors of those individuals who did not possess the focal item. Codes for the different play behaviors were mainly derived from descriptions in the literature on raven play (Ficken, 1977; Heinrich \& Smolker, 1998). They were collapsed into three broad categories: object, locomotor, and social. (See Figure 2 for examples of play in the different categories.) Categories sometimes overlapped. As we were investigating the effect the focal animal's object play had on the other individuals, we focused on behaviors deviating from pure object play.

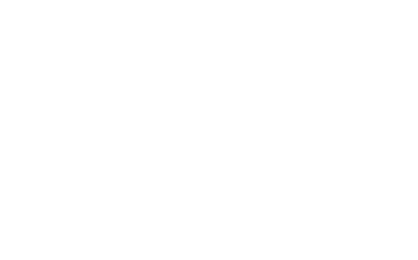

A)

Figure 2. Examples of play behaviors in three broad categories: A) object play, B) locomotor play, C) social play. (Illustration by Helena Osvath).

Object play is marked with one broad code, small object manipulation, encompassing all behaviors where the bird manipulates an object small enough to be moved with its beak or feet, or both. The code has not been applied to larger, unmovable structures such as stones, branches, or the ground. Two other codes also involve small object manipulation; however, as they are part of social or locomotor play, they fall under different codes. (See below.)

Locomotor play included lying on the side or back, hanging in beak or feet from elevated structure, and play flight. During play, ravens occasionally lie on their side or back: a highly conspicuous behavior. Sometimes this is done while holding an object by their feet, which occurred in precisely half the cases in this study. Lying on the side or back can also occur socially; these instances have been handled separately; see below. An equally conspicuous behavior is when a raven hangs from a branch or rope by its feet, upside down, or by its beak, right side up. Play flight requires more precise definition as it can be confused with purposeful locomotion. We chose to define it as flight behaviors that result in a 
return to the starting position: usually a branch. Most instances involve soaring into the wind with continuous change in altitude; a few involved circular acrobatics negotiating the various obstacles in the aviary. Some such cases could be interpreted as social flying. Because the confinements of the aviary made such judgments difficult, all play flights are regarded here as locomotor play.

Social play included co-manipulation of small object, holding one leg of the other with one's foot, and lying on the side or back next to one another (co-lying). Co-manipulation occurs when two (or occasionally more) birds interact at the same time with the same small object. Often, the birds engage in turn taking, pecking or tearing at the object; sometimes, the behavior turns into a tug of war. One bird grabbing the leg of another sometimes leads to one or both falling on their side, lying next to each other. However, such cases were not coded as co-lying if the grip on the other is maintained. Co-lying occurs when two or more birds lie approximately a wing's breadth or less apart from each another. Usually but not always, social play occurs within pairs with established bonds. Social play was never initiated either with or by the bird holding the focal item.

Some potential codes for play have been excluded from analysis. Bathing either in water or snow has been interpreted as play behavior in ravens (e.g., Heinrich \& Smolker, 1998); however, such behavior serves an immediate function as well and so may be governed by motivations other than play. Manipulation of the ground by e.g. digging, scraping, or pecking could likewise occasionally be taken as expression of playful behavior; however, it may also be associated with caching or searching for others' caches. Object caching, which does not serve any obvious biological purpose, has sometimes been interpreted as play (e.g., Heinrich \& Smolker, 1998); however, it may simply be a byproduct of food caching or form of exploration (e.g., Jacobs et al., 2013). We also excluded possible instances of vocal play, due to the difficulties of defining it.

Two codes described social and locomotor play that is occasionally combined with object play: lying on the side or back and co-manipulation of small object. In the primary analysis, we opted to use a hierarchical approach whereby social and locomotor play with objects were not counted as pure object play, because the behavior deviated markedly from the focal animal's. We also did a more conservative analysis where these were regarded as instances of object play; see Results. The few cases where the focal animal engaged in locomotor object play at the same time other individuals initiated play we excluded from analysis, along with all behaviors initiated thirty seconds after the focal animal stopped.

\section{Results}

In the toy condition, the focal item changed holder several times per session: i.e., it was occasionally taken by another bird, sometimes as an apparent instance of tolerated theft. On average, five individuals per session were in possession of the focal item and all subjects possessed the item at some time over the sessions. Only the two most dominant ravens held the item in every session.

In the food condition, the focal item changed holder less: on average, three individuals held the item per session. No one held the food in all sessions. The two most dominant ravens each held the item in seven sessions. The second-to-last raven in the hierarchy never possessed the food, while the most subordinate bird received the food from an experimenter in half of the sessions.

Poisson regression was used to compare the number of play behaviors per ten minutes initiated by an individual under the three conditions. In the toy condition, 1.5 more play behaviors were initiated -3.2 per ten minutes - than in the baseline ( $p<0.001) ; 2.9$ more than in the food condition $(p<0.001)$. Likewise, object play was initiated 1.1 times more frequently -1.2 per ten minutes - than in the baseline $(p=0.25) ; 1.6$ more than in the food condition $(p<0.001)$. Social play was initiated 1.4 times more often -0.8 per ten minutes - than in the baseline $(p=0.013) ; 4.4$ times more often than in the food condition $(p$ $<0.001)$. Locomotor play occurred 2.4 times more often -1.3 per ten minutes - than in the baseline $(p<$ $0.001) ; 7.2$ times more often than in the food condition $(p<0.001)$. See Figure 3 for an overview. Using a conservative measure and regarding the instances of social object and locomotor object play as pure object play, the effects were no different for the toy condition vs. the baseline $(p=0.076)$ or the toy condition vs. the food condition $(p<0.001)$. 


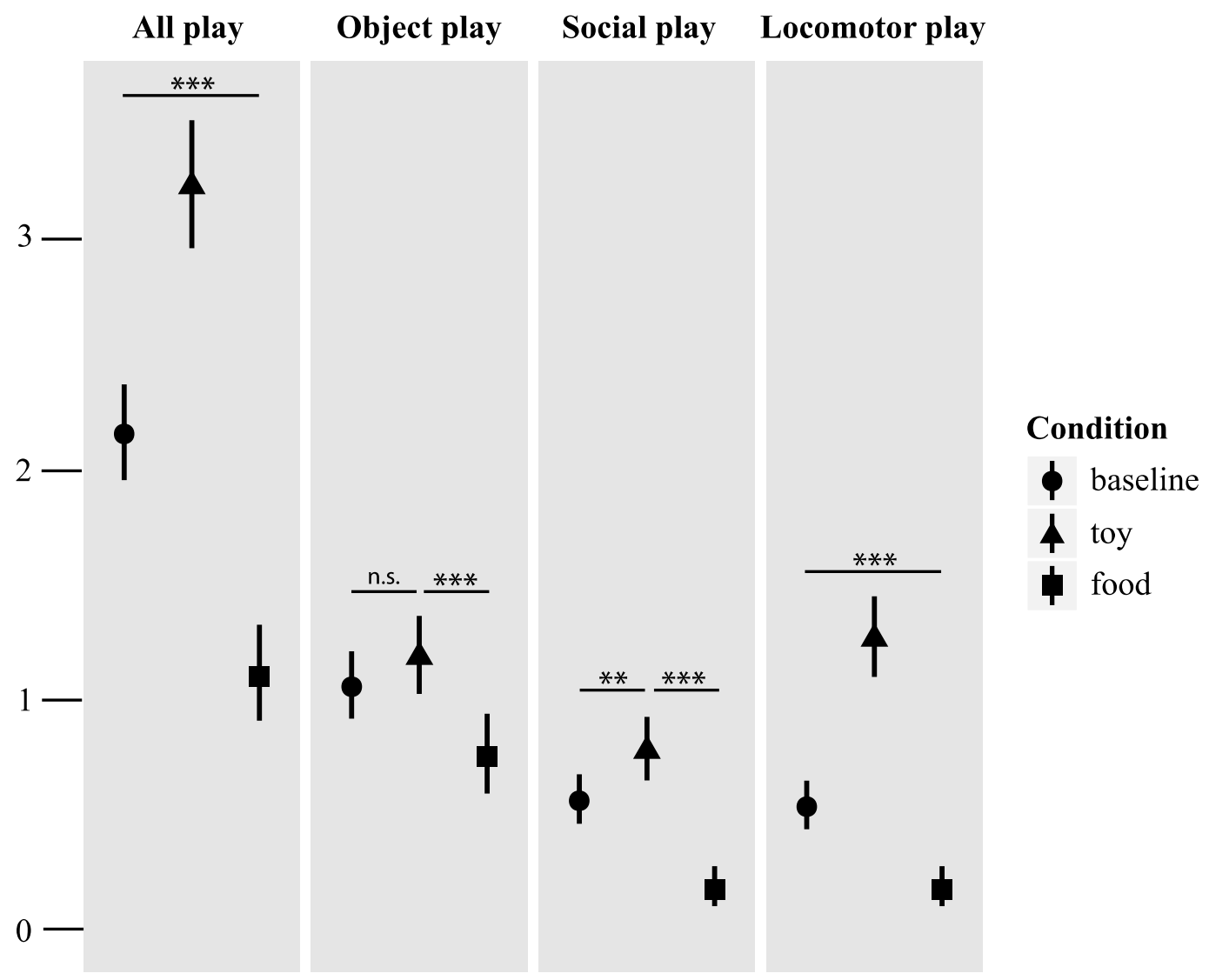

Figure 3. The differences in play behaviors initiated per individual per ten minutes under the different conditions.

In the toy condition, rank and sex of the focal animals had no effect on the occurrence of play in others $(p=0.87)$, excluding the clear outlier of the lowest ranked bird. When the lowest ranked bird $-\mathrm{a}$ female - possessed the toy, others initiated an average of two times more play.

To find out whether the group's initial play behaviors were, indeed, only object play, we also looked at the first five play behaviors per session in the play condition, representing less than a tenth of the average 67 play behaviors per session; see Table 1 for an overview. It could be that any potential contagion begins with behaviors similar to that of the focal bird. In six of the eight sessions, the first play behavior was object play initiated by a non-focal bird. In one session, the first play behavior was locomotor, and in another it was social. Sixty percent of the first five behaviors across the eight sessions were object play, $30 \%$ were locomotor, and $10 \%$ were social. This differs markedly from the overall average of $36.7 \%$ object play, $39.2 \%$ locomotor, and $24.1 \%$ social. However, these differences could be an artifact of the small sample size represented by the first five behaviors per session: an assumption strengthened by similarly large deviations in the baseline condition, which lacked any experimental interventions that might potentially affect initial behaviors. In the baseline condition, object play among the first five behaviors was about 1.5 times more common with social play less than half as common as in the whole dataset. A similarly biased pattern was found in the food condition, where not a single instance of social play was recorded among the first five behaviors per session, compared to over $20 \%$ in the full dataset, while the locomotor play was twice as common in the first five behaviors. 


\section{Discussion}

Regardless of condition, the results indicate a high level of playfulness in sub-adult ravens. The toy condition had significantly higher levels of play behavior than the other two conditions, suggesting a synchronized effect when a favored toy is introduced to the group. More importantly, the toy condition had significantly higher levels of social and locomotor play - even if the animal holding the toy was predominantly engaged in object play. Perhaps surprisingly, we found no difference in object play between the baseline and toy condition. It might be that the objects available in the aviary did not elicit enough interest when a new toy was introduced. Although, one would predict that, if an introduced toy increases motivation for both social and locomotor play, then such elevated motivation should target objects as well. The aviary indeed had abundant small objects such as stones, twigs, plastic packages, and other enrichment materials. Intensified social and locomotor play is not easily explicable as redirected motivation caused by not possessing the desirable item: in the food condition, the introduction of the desirable item seemed rather to inhibit play behavior. In these two conditions, qualitative differences in the motivational states of group members appear to have existed. In any case, some - or many - instances of object play in the play condition could still be the result of contagion - as could, for that matter, some in the baseline, which was not controlled by any interventions.

The results indicate a contagious effect of play mood rather than specific motor patterns. As additional support for this conclusion, at least some play behaviors were likely learned: e.g., hanging upside down from a branch. The spread of learned behaviors does not fit the definition of behavioral contagion (Zentall, 2001); however, the play mood itself is not a learned state, which implies emotional contagion.

In the context of cognitive zoology, the term "emotional contagion" might be confusing; it appears mainly to be used in human psychology. As mentioned, in non-human animals contagion usually refers to species-typical unlearned behaviors such as feeding or fleeing (Zentall, 2001). Emotional contagion is similar, with the crucial difference that the behaviors lead to converging affective states (Hatfield et al., 2009). Naturally, it is difficult to extract affective content from non-linguistic animals, and synchronizing behavior need not necessarily lead to similar states. We believe our study has managed to separate the affective component by showing an increase in play in categories other than those performed by the focal raven.

The precise details of the contagion process remain unclear. One might expect that the initial behaviors picked up by the non-focal birds should be the same as those in the focal raven (i.e., object play). This could then evoke a general play mood that later becomes directed towards locomotor and social play. Analysis of the first five behaviors per session seems not to support such an assumption. Several behaviors are not object play - in some sessions, not even the very first behavior (see Table 1). That said, several of these behaviors might not be the result of contagion. However, the amount of object play is indeed higher than in the overall dataset - though this could, as mentioned, be an effect of sample size. Other types of studies are needed to investigate inception of a contagious process in a group.

This is the first systematic indication of emotional contagion in ravens and, for that matter, birds. It might represent one of the clearest cases of emotional contagion in any non-humans. That said, it is not entirely unexpected that ravens engage in such processes: they are known for their elaborate social skills; for a review see (Bugnyar, 2013). Corvids have been thought of as highly similar to great apes in their complex cognitive skills, including those used in social contexts (Emery \& Clayton, 2004; Seed, Emery, \& Clayton, 2009). In all accounts of such similarities, the process leading to them is assumed to be convergent evolution. The results of the present study might suggest that at least some of the social cognitive skills in common come from parallel evolution. Instead of evolving independently from different underlying structures (convergence), the skills might be arrived at independently through the same developmental patterns (parallelism). If emotional contagion serves similar developmental functions for corvid social cognition as for mammals, this should be the case. The results support - or are at least 
consistent with - the notion that emotional contagion is important to complex sociality. Further research should focus on what function emotional contagion plays in raven cognition and development.

Table 1

The First Five Play Behaviors in Each Session Performed by a Non-focal Bird.

The number after the gender signifies the group rank of the bird within its gender; all males are dominant over all females.

\begin{tabular}{|c|c|c|c|c|c|c|c|c|}
\hline $\begin{array}{c}\text { Order of } \\
\text { play } \\
\text { behavior }\end{array}$ & $\begin{array}{c}\text { Session } \\
1\end{array}$ & $\begin{array}{c}\text { Session } \\
2\end{array}$ & $\begin{array}{c}\text { Session } \\
3\end{array}$ & $\begin{array}{c}\text { Session } \\
4\end{array}$ & $\begin{array}{c}\text { Session } \\
5\end{array}$ & $\begin{array}{c}\text { Session } \\
6\end{array}$ & $\begin{array}{c}\text { Session } \\
7\end{array}$ & $\begin{array}{c}\text { Session } \\
8\end{array}$ \\
\hline 1st & $\begin{array}{c}\text { Social } \\
\text { play } \\
(1-\bigcirc 1)\end{array}$ & $\begin{array}{c}\text { Locomotor } \\
\text { play } \\
\left({ }^{\top} \mathbf{3}\right)\end{array}$ & $\begin{array}{c}\text { Object } \\
\text { play } \\
(\Varangle 3)\end{array}$ & $\begin{array}{l}\text { Object } \\
\text { play } \\
\left({ }^{\top} 1\right)\end{array}$ & $\begin{array}{l}\text { Object } \\
\text { play } \\
\left({ }^{\top} \mathbf{2}\right)\end{array}$ & $\begin{array}{l}\text { Object } \\
\text { play } \\
(+2)\end{array}$ & $\begin{array}{c}\text { Object } \\
\text { play } \\
(\widehat{A})\end{array}$ & $\begin{array}{c}\text { Object } \\
\text { play } \\
(\bigcirc 3)\end{array}$ \\
\hline 2nd & $\begin{array}{c}\text { Object } \\
\text { play } \\
\left(\delta^{\top} 2\right)\end{array}$ & $\begin{array}{c}\text { Locomotor } \\
\text { play } \\
\left(\begin{array}{c}\lambda \\
4\end{array}\right)\end{array}$ & $\begin{array}{l}\text { Object } \\
\text { play } \\
\left(\delta^{\top} \mathbf{2}\right)\end{array}$ & $\begin{array}{l}\text { Object } \\
\text { play } \\
\left({ }^{\top} 1\right)\end{array}$ & $\begin{array}{c}\text { Locomotor } \\
\text { play } \\
\left({ }^{\top} \mathbf{2}\right)\end{array}$ & $\begin{array}{c}\text { Locomotor } \\
\text { play } \\
(\ngtr 1)\end{array}$ & $\begin{array}{c}\text { Locomotor } \\
\text { play } \\
(\lesssim 1)\end{array}$ & $\begin{array}{c}\text { Object } \\
\text { play } \\
(ठ 2)\end{array}$ \\
\hline 3rd & $\begin{array}{c}\text { Locomotor } \\
\text { play } \\
(\precsim \mathbf{3})\end{array}$ & $\begin{array}{l}\text { Object } \\
\text { play } \\
(\bigcirc \mathbf{3})\end{array}$ & $\begin{array}{c}\text { Locomotor } \\
\text { play } \\
(\overbrace{}^{\lambda} 1)\end{array}$ & $\begin{array}{l}\text { Object } \\
\text { play } \\
\left({ }^{\top} 1\right)\end{array}$ & $\begin{array}{l}\text { Object } \\
\text { play } \\
\left({ }^{\lambda} 1\right)\end{array}$ & $\begin{array}{c}\text { Locomotor } \\
\text { play } \\
(+2)\end{array}$ & $\begin{array}{c}\text { Social } \\
\text { play } \\
\left(1-1^{\prime} 1\right)\end{array}$ & $\begin{array}{c}\text { Object } \\
\text { play } \\
(\lesssim \mathbf{4})\end{array}$ \\
\hline 4th & $\begin{array}{c}\text { Locomotor } \\
\text { play } \\
\left(\begin{array}{c}1 \\
1\end{array}\right)\end{array}$ & $\begin{array}{c}\text { Locomotor } \\
\text { play } \\
(\overbrace{}^{\top} \mathbf{3})\end{array}$ & $\begin{array}{c}\text { Locomotor } \\
\text { play } \\
(+3)\end{array}$ & $\begin{array}{l}\text { Object } \\
\text { play } \\
(+2)\end{array}$ & $\begin{array}{l}\text { Object } \\
\text { play } \\
\left({ }^{\top} 1\right)\end{array}$ & $\begin{array}{c}\text { Locomotor } \\
\text { play } \\
\left(\delta^{\lambda} 4\right)\end{array}$ & $\begin{array}{c}\text { Object } \\
\text { play } \\
\left({ }^{\lambda} 1\right)\end{array}$ & $\begin{array}{c}\text { Object } \\
\text { play } \\
(\nmid 3)\end{array}$ \\
\hline 5th & $\begin{array}{c}\text { Object } \\
\text { play } \\
(\delta 2)\end{array}$ & $\begin{array}{c}\text { Social } \\
\text { play } \\
(1-\bigcirc 1)\end{array}$ & $\begin{array}{l}\text { Object } \\
\text { play } \\
(+1)\end{array}$ & $\begin{array}{c}\text { Social } \\
\text { play } \\
\left(1-1_{1}\right)\end{array}$ & $\begin{array}{l}\text { Object } \\
\text { play } \\
(\uparrow 1)\end{array}$ & $\begin{array}{l}\text { Object } \\
\text { play } \\
(+3)\end{array}$ & $\begin{array}{l}\text { Object } \\
\text { play } \\
(\delta 1)\end{array}$ & $\begin{array}{l}\text { Object } \\
\text { play } \\
(\bigcirc 2)\end{array}$ \\
\hline
\end{tabular}

\section{Acknowledgements}

We thank Rasmus Arnling Bååth, Richard Andersson, Elainie Alenkær Madsen, and Tomas Persson for advice and comments and Helena Osvath for artwork. We are also grateful to Stan Kuczaj for inviting this paper. The work was supported by The Crafoord Foundation.

\section{References}

Baldwin, J. D., \& Baldwin, J. I. (1974). Exploration and social play in squirrel monkeys (Saimiri). American Zoologist, 14, 303-315. doi: 10.1093/icb/14.1.303

Baerends, G. P. (1989). On spontaneity in behaviour, the model (fixed) action pattern and play. Netherlands Journal of Zoology, 40, 565-584. doi: 10.1163\%2F156854290X00118

Bekoff, M., \& Byers, J. A. (1981). A critical reanalysis of the ontogeny of mammalian social and locomotor play: An ethological hornet's nest. In K. Immelmann, G. W. Barlow, L. Petrinovich, \& M. Main (Eds.), Behavioral development: The Bielefeld interdisciplinary project (pp. 196-337). Cambridge, UK: Cambridge University Press.

Boyd, R., \& Richerson, P . J. (1988). An evolutionary model of social learning: The effect of spatial and temporal variation. In T. R. Zentall \& B. G. Galef, Jr. (Eds.), Social learning: Psychological and biological perspectives (pp. 29-48). Hillsdale, NJ: Erlbaum. 
Bugnyar, T. (2013). Social cognition in ravens. Comparative Cognition \& Behavior Reviews, 8, 1-12. doi:10.3819/ccbr.2013.80001

Burghardt, G. M. (2005). The genesis of animal play: Testing the limits. London, UK: MIT-press.

Campbell, M. W., \& de Waal, F. B. M. (2011). Ingroup-outgroup bias in contagious yawning by chimpanzees supports link to empathy. PLoS One, 6, e18283. doi: 10.1371/journal.pone.0018283

Emery, N. J., \& Clayton, N. S. (2004). The mentality of crows: Convergent evolution of intelligence in corvids and apes. Science, 306, 1903-1907. doi: 10.1126\%2Fscience.1098410

Fagen, R. (1981). Animal play behavior. Oxford, UK: Oxford University Press.

Ficken, M. S. (1977). Avian play. The Auk, 94, 573-582.

Gamble, J. R., \& Cristol, D. A. (2002). Drop-catch behaviour is play in herring gulls, Larutus argentatus. Animal Behaviour, 63, 339-345. doi: 10.1006/anbe.2001.1903

Gomendio, M. (1988). The development of different types of play in gazelles: Implications for the nature and functions of play. Animal Behaviour, 36, 825-837. doi: 10.1016\%2FS0003-3472\%2888\%2980165-9

Gwinner, E. (1966). Über einige Bewegungsspiele des Kolkraben. Zeitschrift für Tierpsychologie, 23, 28-36. doi: 10.1111/j.1439-0310.1966.tb01587.x

Hatfield, E., Rapson, R. L., \& Le, Y. L. (2009). Primitive emotional contagion: Recent research. In J. Decety \& W. Ickes (Eds.), The social neuroscience of empathy (pp. 19-30). Boston, MA: MIT Press.

Heinrich, B., \& Smolker, R. (1998). Play in common ravens (Corvus corax). In M. Bekoff \& J. A. Byers (Eds.), Animal play: Evolutionary, comparative, and ecological perspectives (pp. 27-44). Cambridge, UK: Cambridge University Press

Held, S. D. E., \& Špinka M. (2011). Animal play and animal welfare. Animal Behaviour, 81, 891-899. doi: 10.1016\%2Fj.anbehav.2011.01.007

Jacobs, I. F., Osvath, M., Osvath, H., Mioduszewska, B., von Bayern, A.M.P., \& Kacelnik, A. (2013). Object caching in corvids: incidence and significance. Behavioural Processes 102, 25-32 doi:10.1016/j.beproc.2013.12.003

Langford, D. J., Crager, S. E., Shehzad, Z., Smith, S. B., Sotocinal, S.G., ...Mogil, J. S. (2006). Social modulation of pain as evidence for empathy in mice. Science. 312, 1967-1970. doi: dx.doi.org/10.1126\%2Fscience. 1128322

Madsen, E. A., \& Persson, T. (2013). Contagious yawning in domestic dog puppies (Canis lupus familiaris): the effect of ontogeny and emotional closeness on low-level imitation in dogs. Animal Cognition, 16, 233-240. doi: 10.1007/s10071-012-0568-9

Mancini, G., Ferrari, P. F., \& Palagi, E. (2013). Rapid facial mimicry in geladas. Scientific Reports, 3. doi: $10.1038 /$ srep01527

Pellis, S. M., \& McKenna, M., (1992). Intrinsic and extrinsic influences on play fighting in rats: Effects of dominance, partner playfulness, temperament and neonatal exposure to testosterone propionate. Behavioural Brain Research, 50, 135-145. doi: 10.1016/S0166-4328(05)80295-5

Preston, S. D., \& de Waal, F. B. M. (2002). Empathy: Its ultimate and proximate bases. Behavioral and Brain Sciences, 25, 1-72. doi: 10.1017/S0140525X02000018

Ross, M. D., Menzler, S., \& Zimmermann, E. (2008). Rapid facial mimicry in orangutan play. Biology Letters, 4, 27-30. doi: 10.1098/rsbl.2007.0535

Seed, A., Emery, N., \& Clayton, N. (2009). Intelligence in corvids and apes: A case of convergent evolution? Ethology, 115, 401-420. doi: 10.1111\%2Fj.1439-0310.2009.01644.x

Tolman, C. W. (1964). Social facilitation of feeding behaviour in the domestic chick. Animal Behaviour, 12, 245251. doi: 10.1016/0003-3472(64)90008-9

Varlinskaya, E. I., Spear, L. P., \& Spear, N. E. (1999). Social behavior and social motivation in adolescent rats: Role of housing conditions and partner's activity. Physiology and Behavior, 67, 475-482. doi: 10.1016/S00319384(98)00285-6

de Waal, F. B. M. (2008). The evolution of empathy. Annual Review of Psychology, 59, 279-300. doi: 10.1146\%2Fannurev.psych.59.103006.093625

Zentall, T. R. (2001). Imitation in animals: Evidence, function, and mechanisms. Cybernetics and Systems, 32, 5396. doi: 10.1080/019697201300001812

Zentall, T. R. (2004). Action imitation in birds. Learning and Behavior, 32, 15-23. doi: 10.3758\%2FBF03196003 